\title{
Suicidal Risk: Definition, Contexts, Differential Diagnosis, Neural Correlates and Clinical Strategies
}

\author{
Giulio Perrotta \\ Director of the Department of Criminal and Investigative Psychology UNIFEDER, Italy. \\ Corresponding Author: Giulio Perrotta, Directorofthe Department of Criminaland Investigative Psychology UNIFEDER, Italy. \\ Received date: January 27, 2020; Accepted date: February 12, 2020; Published date: February 17, 2020 \\ Citation: Perrotta G. (2020) Suicidal risk: definition, contexts, differential diagnosis, neural correlates and clinical strategies. J. Neuroscience and \\ Neurological Surgery, 6(2); Doi:10.31579/2578-8868/114
}

Copyright: (c) 2020 Giulio Perrotta, This is an open-access article distributed under the terms of The Creative Commons Attribution License, which permits unrestricted use, distribution, and reproduction in any medium, provided the original author and source are credited.

\begin{abstract}
Starting from the concept of suicidal risk, this work re-elaborates the main theories on the theme and related theme of mourning, proceeding with a complete examination of the possible differential diagnoses and of the neural correlates involved, up to the most suitable clinical strategies to avoid the event of death.
\end{abstract}

Key words: psychology, neuroscience, depressive disorder, suicidal risk, suicide, death, psychotherapy,

psychopharmacology, benzodiazipines, antidepressants, mood stabilizers, strategic approach.

\section{Index:}

1. Definitions, differential diagnosis and clinical contexts of the suicidal risk

2. The neural correlates in suicidal contexts

3. Clinical strategies for the management of the suicidal risk

4. Conclusions

5. References

\section{Definition, differential diagnosis and clinical contexts of the suicidal risk}

In common parlance, suicide (from Latin "sui caedere") is the physical act by which the person deliberately procures death; it is an extreme selfinjurious gesture, which underlies the existence of a serious condition of psychological distress, be it caused by pathology or by unfortunate events of a personal nature (social, economic, work, environmental), but it can also be determined by a temporary state of psychic inability resulting from a non-psychiatric medical condition. [3]

From an epidemiological point of view, the suicide rate varies according to the geographical area, the sex of the subject, the age of the subject, the previous pathological conditions and the more or less dysfunctional context of the environment that welcomes the person. With these assumptions, drawing up rankings or statistical reports, in the writer's opinion, is completely useless, because the data would change quickly and the photograph that would emerge would be only useful in that historical moment and for that geographical profile. [1] However, it is interesting to note that not all of these risk factors are of equal severity: mental disorders, for example, affect almost 50\% of nefarious events, while problems in married life and emotional crises and physical problems account for $30 \%$, as well as problems at work and financial problems, which instead affect in $15 \%$ of cases. [6] However, it is often a combination of these events that determines suicidal risk. [1]
The sociologist in Émile Durkheim, first, analyzed this phenomenon in depth, hierarchizing it and classifying it methodically, distinguishing four different types connected to equally four degrees of integration and social regulation: selfish; altruistic; fatalistic; anomic. In the first case, the subject is driven by attitudes and behaviors aimed at achieving personal interest, in the absence of a weighting of the interests of others, harmful or not to the intimate and private sphere of the surrounding environment; in the second case, the subject is driven by the belief that this decision is more or less necessary to alleviate someone else's pain or is necessary to help or save someone; in the third case, the subject while determining the final event is subject to the providential rules of fate, being the victim of adverse circumstances; in the fourth case, it is the event itself that is the standard sign of social change, meaning the author - by anomia - a state of change between normative expectations and lived reality, whether acute (usually follows a sudden change, such as the death of a relative) or chronic (usually following a sudden change, such as the death of a relative). [2] [5]

In the clinical setting, suicidal risk represents the typical variable in the presence of some well-identified psychopathologies, such as depressive disorder, bipolar disorder, personality disorders, somatic disorders, posttraumatic stress disorder, eating disorders, sleep disturbances, substance addiction, behavioral addiction (e.g. pathological gambling), burn-out syndrome and psychotic disorders (including schizophrenia). [3]

Of particular relevance is mourning, which can significantly affect the onset of suicidal ideas, especially if the link with the deceased was particularly close or significant. Already in DSM-IV-TR mourning had been placed among the so-called "conditions that may be the object of clinical attention", precisely to indicate how, in the normal processing process following this event, there could be difficulties such as to render the condition of the pathological survivor. However, the manual envisaged the possibility of veering towards a diagnosis of a major depressive episode if the symptoms and functional impairment persisted for more than two months, thus making the consequences of the failure to 
process mourning fall within a more depressive context. The DSM-5 therefore proposed the diagnosis of persistent and complicated mourning disorder to indicate precisely those conditions in which the acute manifestations of mourning, with negative experiences, of sadness, guilt, envy, anger, associated with persistent ruminations related to the causes, circumstances and consequences of the loss remain if at least twelve months have passed since the death of someone with whom the grieving individual had a close relationship, considering this period of time as discriminating between normal and pathological mourning. Furthermore, this disorder is frequently accompanied by sleep disturbances, hyperexia, asthenia and easy fatigue, as well as the intensification of dysfunctional behaviors such as the use of alcohol or drugs. The diagnostic criteria for persistent and complicated mourning disorder are:

a) the individual experienced the death of someone with whom he had a close relationship;

b) since death, at least one of the following symptoms has been present for more days than it was not present and at a clinically significant level of severity, and has persisted in adults at least twelve months and in children for at least six months after mourning:

1. a persistent desire / nostalgia for the deceased person. In young children, desire can be expressed in play and behavior also through behaviors that reflect being separated from, and also reunited with, a caregiver or another figure object of attachment;

2. sadness and intense emotional pain following death;

3. concern for the deceased;

4. concern about the circumstances of death. In children, this concern for the deceased can be expressed through the content of the game and the behavior can extend to concern for the possible death of other close people.

c) since death, at least six of the following symptoms have been present for more days than they were not present and at a clinically significant level of severity, and have persisted in adults at least twelve months and in children at least six months after mourning:

1) suffering related to death:

- marked difficulty in accepting death. In children this difficulty depends on the ability to understand the meaning and definitiveness of death.

- feeling disbelief or emotional numbness about loss.

- difficulty abandoning oneself to positive memories concerning the deceased.

- bitterness or anger in relation to loss.

- negative self-assessment in relation to the deceased or the death (e.g. sense of self-guilt).

- excessive avoidance of memories of loss (e.g. avoidance of people, places or situations associated with the deceased; in children this may include the avoidance of thoughts and feelings about the deceased.

2) social and identity disorder.

3) desire to die to be close to the deceased.

4) from the moment of death, difficulty in trusting towards the others.

5) from the moment of death, feeling of being alone or detached from others.

6) feeling that life is empty or meaningless without the deceased, or thought of not making it without the deceased.

7) confusion about one's role in life, or diminished sense of one's identity (e.g. a part of oneself has diminished together with the deceased).

8) from the moment of loss, difficulty or reluctance to pursue their interests or making plans for the future (e.g. friendships, activities). d) the disorder causes clinically significant distress or impaired functioning in the social, occupational, or other important areas.

e) the mourning reaction is disproportionate or inconsistent with cultural or religious norms or age-appropriate.

The "suicidal risk" is nothing more than a series of circumstances capable of fueling the subject's suicidal ideation, prompting him to carry out self-injurious acts of different intensity and severity. [1] On these assumptions, the suicide has different degrees: in its chronic form it is the "actual suicide", where the subject gets to inflict himself with a selfinjurious act so serious as to reach the event of death; in its acute form is "attempt", a non-fatal, self-inflicted, potentially harmful act intended to cause death but may or may not cause injury; in its mild form it is the "non-suicidal self-harm" act, which despite being dangerous does not cause damage aimed at the event of death. [3]

In particular, the self-injurious act performs different functions: the most accredited ones concern an emotional regulation strategy, a form of "learned" self-punishment due to a critical and invalidating life context, and again, an attempt to exit from dissociative states. In DSM-IV, selfharm is included among the symptoms of borderline personality disorder: "recurrent threats, gestures, suicidal behaviors or self-mutilating behavior". However, although some research has confirmed the existence of a strong relationship between self-harm and this personality disorder, even patients who receive other diagnoses seem to get injured in an intentional and deliberate way. In particular, subjects suffering from major depression, anxiety disorders, substance abuse, eating disorders, post-traumatic stress disorder, schizophrenia and other serious personality disorders. In addition, recent studies have investigated the existence or absence of an association between intentional self-harm and para-suicidal and suicidal gestures. It was initially hypothesized that these behaviors may be located along a continuum. However, no-suicidal self-harm gestures and para-suicidal gestures would seem to differ for some important points, including the use of different methods, physical outcomes of different severity (greater for para-suicidal and suicidal gestures) and different intentionality (no-suicidal self-harm is frequently implemented in the absence of suicidal ideation). This distinction turns out to be the starting point for the proposal made in the current diagnostic manual: no-suicidal self-harm could be conceived as a separate diagnostic category. [3]

The criteria proposed in the current diagnostic manual indeed include [3]:

a) in the last year, in five or more days, the individual has intentionally inflicted damage of some kind to the body surface capable of inducing bleeding, bruising or pain (for example, cutting, burning, stabbing, hitting himself, rubbing himself excessively), with the expectation that the injury will lead to only minor or moderate physical damage (there is no suicidal intentionality).

b) the individual is involved in self-harm activities with one or more of the following expectations:

1. get relief from a negative feeling or cognitive state;

2. solve an interpersonal difficulty.

3 . induce a positive feeling.

c) self-harm is associated with at least one of the following symptoms:

1. Interpersonal difficulties or negative sensations or thoughts, such as depression, anxiety, tension, anger, generalized discomfort, self-criticism, which occur in the period immediately preceding the self-injurious gesture.

2. before making the gesture, there is a period of concern that is difficult to control regarding the gesture that the individual intends to commit. 
3. self-injurious thoughts frequently present, even when the behavior is not implemented.

Suicidal risk is also connected and aggravated by some physical pathologies, such as in the case of cancer, systemic viral infections (HIV and hepatitis), chronic pain, cerebral ischemias and chronic autoimmune diseases, dementias and brain vasculopathies, as well as deficiencies chronic vitamin D and B complex, calcium or excess gold, iron, copper and zinc. [3]

\section{The neural correlates in suicidal contexts}

There is no known underlying pathophysiology unique to suicide or depression. [7] However, it is believed to be the result of multiple behavioral, socio-environmental and psychiatric factors. [8] Low levels of the brain neurotrophic factor (BDNF) are directly related to suicide [9] and indirectly through their role in major depression, post-traumatic stress disorder, schizophrenia and obsessive-compulsive disorder. [10] Postmortem studies have found a reduction in BDNF levels in the hippocampus and prefrontal cortex, both in suicides with psychiatric conditions and in those without. [11] Serotonin, a brain neurotransmitter, is believed to be particularly scarce in those who die from suicide. This belief is partly based on evidence of an increase in 5-HT2A receptor levels after death. [12] Other tests include reduced levels of a degradation product of serotonin, 5-hydroxyindolacetic acid, in the cerebrospinal fluid. [13] However, direct evidence is difficult to gather. [12] Epigenetics, the study of variations in gene expression in response to environmental factors that do not alter DNA, is also believed to be useful for playing a role in suicide risk. [14]

\section{Clinical strategies for the management of the suicidal risk}

A healthcare professional who suspects the possibility of a patient's suicide is required to inform an authorized service to intervene, as happens if he were a family member, an acquaintance or an unknown person; the sanction provided for by most legal systems is the omission of relief, a crime punishable by imprisonment and a financial penalty. [1]

Precisely because they are fragile, these subjects should not be left alone until they are placed in a protected environment. They must be transported to a safe place (often a psychiatric facility) and by trained professionals (eg, ambulance, police). [1]

Any suicidal act, regardless of whether it is a demonstration gesture or a purposeful attempt, must be seriously considered and just as every person with a serious self-inflicted injury must be assessed and treated as a consequence of the physical injury, each person who presents signs clear clinicians of suicidal behavior must be content and protected. [1]

The initial assessment can be performed by any member of the health care professional qualified in the assessment and management of suicidal behavior. However, all patients require a psychiatric evaluation as soon as possible. A decision must be made about the patient's need for hospitalization, and whether forced hospitalization or temporary containment is necessary. Patients with psychotic disorder and those with severe depression and unresolved crisis must be hospitalized in a psychiatric unit, while patients with manifestations of potentially confounding medical disorders (e.g. delirium, seizures or fever) may need to be hospitalized in a facility medicine adapted to the appropriate precautions against suicides. Greater sensitivity is needed if the patient has a previous clinical history that could suggest suicidal behavior. The psychiatric evaluation will then identify some of the problems that contributed to the attempt and help the doctor plan appropriate treatment. It includes the following steps: establishing a relationship and listening to the patient's narrative; understand the reasons for the suicide attempt, what is the background, the events that preceded it and the circumstances in which it occurred; investigate symptoms of mental disorders that are associated with suicide; fully evaluate the patient's mental state, with particular regard to the identification of depression, anxiety, agitation, panic attacks, severe insomnia or other mental disorders, as well as alcohol or substance abuse (many of these problems require specific treatment, in addition to critical intervention); adequately understand the family and personal relationships that are often related to the suicide attempt; hold interviews with close family and friends; investigate the presence of a firearm in the house; safety planning to help patients identify suicide planning triggers and develop plans to deal with suicidal thoughts when they occur. [15] [16]

However, suicide prevention is the first active form of anticipating the problem, while requiring careful identification of people at risk. This is not always easy, as some risk signals can be silent and not clearly manifested. The most vulnerable age groups are certainly the "hinges", those that represent changes and events, such as adolescence, adulthood and old age. But still social situations such as special anniversaries, professional unemployment, economic upsets, legal problems and environmental isolation are all signs of a highly typical context for the establishment of suicidal thoughts or tendencies towards self-harm. Furthermore, previous suicide attempts, psycho-physical pathological history similar to suicide, typical clinical features such as mood deflection, depression, delusions, hallucinations, hostile or impulsive personality and chronic diseases are other typical conditions that facilitate the onset of ideation. suicidal. Finally, substance abuse, including drugs, complete the picture. [1]

With reference to the best clinical therapy, undoubtedly the combination of psychotherapy and psychopharmacology has given the best results. Identifying the morbid psychic condition is the first step to stop the spiral, possibly giving the targeted drug, with a therapy adapted to the person and frequent visits, at least in the first trimester (even three times a week, then falling to one a week in the following three months). [3]

\section{Conclusions}

In common parlance, suicide (from Latin "sui caedere") is the physical act by which the person deliberately procures death; it is an extreme selfinjurious gesture, which underlies the existence of a serious condition of psychological distress, be it caused by pathology or by unfortunate events of a personal nature (social, economic, work, environmental), but it can also be determined by a temporary state of psychic inability resulting from a non-psychiatric medical condition. [3]

\section{References}

1. Perrotta G., Psicologia generale. Luxco ed., I ed., 2019.

2. Perrotta G., Psicologia dinamica. Luxco ed., I ed., 2019.

3. Perrotta G., Psicologia clinica. Luxco ed., I ed., 2019.

4. Pompili M., Imperio T., Erbuto D., Depressione e Suicidio. Focus on Brain, n. 3, vol 1, feb 2018.

5. Durkheim É., Il suicidio-L'educazione morale, UTET, 2008, p. 238, ISBN 978-88-02-07953-0. 
6. American Psychiatric Association's Practice Guideline, Assessment and Treatment of Patients With Suicidal Behaviors, 2018:

7. B Chang, Gitlin, D.; Patel, R., The depressed patient and suicidal patient in the emergency department: evidence-based management and treatment strategies., in Emergency medicine practice, vol. 13, n 9, 2011 Sep, pp. 1-23, PMID 22164363.

8. PS Yip et al., Means restriction for suicide prevention., in Lancet, vol. 379, nº 9834, 23 giugno 2012, pp. 2393-2399,

9. M Pjevac e Pregelj, P, Neurobiology of suicidal behaviour, in Psychiatria Danubina, 24 Suppl 3, October 2012, pp. S33641, PMID 23114813.

10. L Sher, The role of brain-derived neurotrophic factor in the pathophysiology of adolescent suicidal behavior, in International journal of adolescent medicine and health, vol. $23, n^{\circ} 3,2011$, pp. 181-185,
11. L Sher, Brain-derived neurotrophic factor and suicidal behavior, in QJM : monthly journal of the Association of Physicians, vol. 104, nº 5, May 2011, pp. 455-458,

12. Yogesh Dwivedi, The neurobiological basis of suicide, Boca Raton, FL, Taylor \& Francis/CRC Press, 2012, p. 166,

13. George Stein e Wilkinson, Greg, Seminars in general adult psychiatry, 2. ${ }^{\text {e }}$ ed., London, Gaskell, 2007, p. 145,

14. AE Autry e LM Monteggia, Epigenetics in suicide and depression, in Biological Psychiatry, vol. $66, \mathrm{n}^{\circ} 9,1^{\circ}$ novembre 2009, pp. 812-3,

15. Michel K, Valach L, Gysin-Maillart A: A novel therapy for people who attempt suicide and why we need new models of suicide. Int J Environ Res Public Health 14 (3), 2017. pii: E243.

16. Stanley B, Brown G: Safety planning intervention: A brief intervention to mitigate suicide risk. Cogn Behav Pract 19: 256264, 2011.
This work is licensed under Creative Commons Attribution 4.0 License

To Submit Your Article Click Here: Submit Article

DOI:10.31579/2578-8868/114
Ready to submit your research? Choose Auctores and benefit from:

* fast, convenient online submission

* rigorous peer review by experienced research in your field

* rapid publication on acceptance

* authors retain copyrights

* unique DOI for all articles

* immediate, unrestricted online access

At Auctores, research is always in progress.

Learn more http://www.auctoresonline.org/journals/neuroscience-andneurological-surger 